\title{
The Neolithic Revolution : Domestication of Plants Explained
}

\author{
by Rochelle Forrester \\ Copyright (C) 2019 Rochelle Forrester \\ All Rights Reserved \\ The moral right of the author has been asserted
}

Anyone may reproduce all or any part of this paper without the permission of the author so long as a full acknowledgement of the source of the reproduced material is made.

Second Edition

Published 30 September 2019

Preface

This paper was written in order to examine the order of discovery of significant developments in the history of humankind. It is part of my efforts to put the study of social and cultural history and social change on a scientific basis capable of rational analysis and understanding. This has resulted in a hard copy book How Change Happens: A Theory of Philosophy of History, Social Change and Cultural Evolution and a website How Change Happens Rochelle Forrester's Social Change, Cultural Evolution and Philosophy of History website. There are also philosophy of history papers such as The Course of History, The Scientific Study of History, Guttman Scale Analysis and its use to explain Cultural Evolution and Social Change and the Philosophy of History and papers on Academia.edu, Figshare,

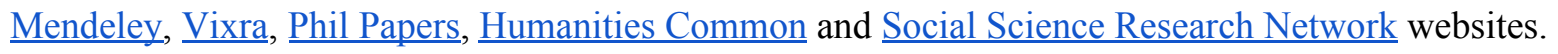

This paper is part of a series on the History of Science and Technology. Other papers in the series are

The Invention of Stone Tools $\quad \underline{\text { Fire }}$ The Discovery of Agriculture The Invention of Pottery

History of Metallurgy The Development of Agriculture and Pastoralism $\quad$ History of Writing

The Invention of Glass History of Astronomy Invention of Microscopes and Telescopes

History of Printing The Discovery of Steam Power History of Electricity

$\underline{\text { Electric Telegraph }} \underline{\text { Telephone }} \underline{\text { Radio }} \underline{\text { Television }} \underline{\text { Photography Motion Pictures }}$

Internal Combustion Engine Motor Car Aeroplanes The History of Medicine

The Discovery of the Periodic Table The Discovery of the Atomic World

Other papers by Rochelle Forrester include works on Epistemology and the Philosophy of Perception such as Sense Perception and Reality and on quantum mechanics such as the Quantum Measurement Problem and The Bohr and Einstein debate on the meaning of quantum physics. Rochelle Forrester's 
work is also published on Slideshare, Issuu and Scribd. Rochelle Forrester is a member of the International Network for Theory of History.

\begin{abstract}
This paper is written to question the widespread belief among anthropologists that prehistoric hunter gatherers knew about agriculture long before agriculture began to be practiced. The paper suggests gradually accumulating human knowledge led to the development of agriculture rather than population pressure, favorable mutations or convenient climate, all of which would have occurred at various times long before agriculture was developed, without leading to the discovery of agriculture.
\end{abstract}

The domestication of plants and animals has been a much discussed event in prehistory and anthropology. It has however been much troubled by a lack of any firm knowledge of how the process took place. Most attention has focused on trying to identify when, where and in what circumstances agriculture first emerged. Why agriculture emerged has usually been explained by its offering significant economic advantages to human populations over that which would be provided by the hunting and gathering lifestyle. This has been called into question by recent studies of modern hunter-gatherers which suggest hunter-gathering may be a better lifestyle than previously imagined. However, if this is true and if it is possible to use studies of modern hunter-gatherers to assess the living conditions of hunter-gatherers before the agricultural revolution, then it is necessary to explain why humans took to agriculture and why they did it, when they did.

A further point that needs to be explained is why most of humanity took to agriculture at the same time. Anatomically modern humans, Homo sapiens sapiens emerged around 200,000 years ago in Africa. For approximately 190,000 of those years they obtained their food by hunting and gathering. Then within a period of about 8,000 years the great majority of humanity were making their living by farming. Why such a long wait, followed by the spread of agriculture across a large part of the land inhabited by humans. Obviously diffusion of agricultural knowledge is an explanation for its rapid spread in this 8,000 year period, but it seems clear that agriculture was independently invented in a number of areas and most certainly in the new world.

Various explanations have been put forward for the development of agriculture. One involves plant mutations such as mutant maize, but such mutations would have been available many times before agriculture was developed, but were ignored. When agriculture developed, a wide variety of different crops were domesticated, and it is hardly likely that they all developed convenient mutations at approximately the same time without those mutations occurring many times previously. We need to explain why the human population took advantage of the mutations, if that was how agriculture developed, when they did and why they had previously ignored the mutations.

Another explanation is that the right conditions for agriculture developed due to climate change that preceded the development of agriculture. However this explanation has the problem that many different climates would have existed on earth during the 190,000 years that Homo sapiens sapiens inhabited the earth before the development of agriculture. Many of these climates would have been just as suitable for the development of agriculture as the climates in which agriculture eventually developed. Yet agriculture did not develop until some 10,000 years ago despite the presence of suitable climates for the 
development of agriculture in the preceding 190,000 years of Homo sapiens sapiens occupation of the planet.

An alternative explanation for the development of agriculture is that it was forced by population pressure. The problem with this view is that it does not explain how humans learnt to engage in agriculture and why there was population pressure at that particular time 10,000 years ago but not at other times in human prehistory. The human population through most of this time was able to expand into new lands, such as America, but the population in Africa, Europe and the Middle East were not able to expand into new lands in the way that the North East Asian population was able to expand. Local population pressures would have developed many times in prehistory but did not give rise to the development of agriculture. Before humans began to move into America and Australia, they had for several hundreds of thousands of years occupied all of Africa, Europe and Asia and despite population pressure, never developed agriculture. The population theory says that agriculture developed in the Middle East because humankind ran out of room to expand in South America, as though the people of the Middle East felt population pressure 10,000 years ago due to humankind running out of room to expand in South America. It is hardly likely the people of the Middle East would have felt population pressure due to events in South America. In the modern world, with its advanced transport and communications, some countries such as Japan are arguably over populated yet it does not have much effect on other countries. It would seem likely due to excessive migration into fertile areas, or due to once fertile areas becoming less fertile, there would be excessive population pressure on the land at many times in prehistory, but there is no evidence that this ever lead to the development of agriculture.

Many of the proposed explanations for the development of agriculture have the common defect of not being able to explain why agriculture developed when it did, and not before, as the proposed explanations involve conditions which almost certainly existed many times before agriculture was actually developed. The only plausible explanations of the development of agriculture are those that are able to answer the question of why agriculture did not develop before 10,000 year ago.

One explanation that does not suffer from this problem is that suggested by L H Morgan (1877) and V Gordon Childe (1955) and others that agriculture developed as part of a natural process of cultural evolution when a certain level of knowledge and technology had developed. This view has been much criticized in the last twenty or thirty years due to research into modern hunter-gatherer societies. This research suggests that the knowledge that plants grow from seeds was available to hunter-gatherers in prehistory.[i] Evidence cited in support of this position is that modern hunter-gatherers understand agriculture and that hunter-gatherers must inevitably have a considerable knowledge of the plants and animals they live off. It is claimed there is no significant difference between the knowledge hunter-gatherers have of the plants and animals they needed for their survival and the knowledge of plants and animals required for agriculture and domestication.[ii] There is a problem with this as obviously modern hunter-gatherers could and would have learnt plants are grown from seeds from 10,000 years of contact with agrarian societies.

The claim that modern hunter-gatherers having a knowledge of agriculture, shows that prehistoric hunter-gatherers knew about agriculture is a logical error. It is literally a non-sequitur in that it does not follow that modern hunter-gatherers knowing of agricultural, means prehistoric hunter-gatherers knew how to engage in agriculture. This is because modern hunter-gatherers would have inevitably known of agriculture from thousands of years of contact with agrarian societies. This means there is no evidence at all for the belief that prehistoric hunter-gatherers knew how to practice agriculture. 
More specifically the logical error is that of the fallacy of composition. The fallacy claims that because a part of the whole has a particular characteristic, then all parts of the whole have that characteristic. The claim is that as some hunter-gatherers (ie modern hunter-gatherers) know about agriculture, then all hunter-gatherers know about agriculture. This obviously does not follow as there is no reason to believe, just because some hunter-gatherers, know about agriculture, all will.

It is quite difficult to find hunter-gather groups that have had no contact with agrarian societies. Where there are such hunter-gatherers they do not seem to understand that plants grow from seeds. The Australian Aborigines were quite familiar with the seeds of various grasses, but they seemed to be unaware that the grasses and other plants grow from seeds.[iii] An analogous situation between seeds and plants is between sex and giving birth. The Australian Aborigines believed a woman became pregnant when a spirit being enters her body and before contact with Indonesians and Europeans seemed to have little understanding of the relationship between sex and pregnancy.[iv] They do not seem to be alone in this; the Trobriand Islanders studied by Malinowski seemed to be in the same position. If hunter-gatherers are unable to work out the relationship between sex and giving birth, both matters they were closely involved with; it seems unlikely they would understand the relationship between seeds and plants, things which while they have some familiarity with, they would not be as familiar with as they would be with sex and child-birth.

A similar situation exists with the belief from the time of the ancient Greeks to the mid-19th century in the spontaneous generation of life forms from non-living matter. Certain life forms such as maggots, bees, mice and others were considered to arise spontaneously from other matter such as hay or decaying plant or animal matter. Spontaneous generation was eventually only disproved by experiments by Pasteur and the development of powerful microscopes in the mid-19th century. If a literate society, well acquainted with the rules of logic, continued to believe in spontaneous generation some hundreds of years after the start of modern science, then it is very likely that prehistoric hunter-gatherers would have been unlikely to work out that plants come from seeds. The most probable and plausible belief for prehistoric hunter-gatherers as to the source of plants, given their knowledge at the time, was spontaneous generation from the earth. Alternatively, prehistoric hunter-gatherers may have believed plants come from the gods or some other supernatural cause.

A further point is that if it was true that the knowledge of agriculture and domestication was known to hunter-gatherers before agriculture and domestication became common, then one would expect to find some evidence of agriculture and domestication long before 10,000 years ago. It is hardly likely that the conditions (whatever they were) that lead to the development of agriculture some 10,000 years ago; never occurred in the previous 190,000 years Homo sapiens sapiens has been on this planet. One would expect to find evidence that where the conditions were right agriculture was practiced and then if the conditions later turned against agriculture it would be abandoned. Such evidence exists with "lost cities" in America and Zimbabwe, but these cities were obviously built long after the discovery of agriculture some 10,000 years ago. It seems clear that agriculture only developed 10,000 years ago and then by both diffusion and independent invention was adopted by the great majority of human beings. This hardly supports the idea that the knowledge required for agriculture was widely known amongst hunter-gatherers prior to 10,000 years ago.

A further problem for the idea that early hunter-gatherers had knowledge sufficient for agriculture is that they could, to borrow a phrase from Thomas Kuhn and The Structure of Scientific Revolutions, be considered to be living in a different paradigm from the people who practice agriculture. Hunter-gatherers 
are interested in where the food is and how to get it. Farmers however are interested in how to make plants grow. They need to know about the planting of seeds, the creation of clearings, which plants grow best in which soils, the enrichment of soils and the watering of their gardens, the importance of removing weeds, conservation measures such as are involved with shifting agriculture and how plants can be improved by a process of selection. These sorts of measures, necessary for successful agriculture, will not be obvious to hunter-gathers. Plants growing wild, the only plants known to pre-agriculture hunter-gatherers grow without being in specially cleared areas. Which soils plants grow best in is of no interest to hunter-gatherers, they are looking for plants not soil types. That plants grow better when the soil is enriched and weeds are removed would not be obvious to hunter-gatherers. That nutrients in the soil get exhausted after a few crops and it is necessary to plant additional crops at a new location, or to let the land lie fallow, would not be obvious to hunter-gatherers. Knowledge of these things could only be developed by trial and error, not by simple observation of wild plants. It could only be developed by the actual practice of agriculture. The most hunter-gatherers could learn simply by observation would be that plants require water and that plants grow well in areas cleared by fire. As much of what is needed for successful agriculture can only be learnt by trial and error and not by the observation of wild plants it seems that pre-agricultural hunter-gatherers could not have had the knowledge required for agriculture. Present day hunter-gatherers may well have that knowledge but it is obvious they could and would have learnt that knowledge from contact with agrarian peoples over thousands of years. That of course is one of the ways the diffusion of agriculture occurred. However when the environment of the hunter-gatherers, who had learnt of agriculture, was unsuitable for agriculture, then the hunter-gatherer lifestyle continued.

A final problem for the idea that hunter-gatherers in prehistoric times knew plants grow from seeds is that this idea is far from obvious. Seeds look quite unlike plants, so there is no reason to believe they will eventually grow into plants. There is also a significant time period before seeds turn into plants so that it is not obvious the seeds will become plants. Finally, in many cases, seeds will not grow into plants, due to factors such as poor soils, lack of water or to many weeds.

A similar situation exists with the domestication of animals. The earliest domestic animals are believed to be dogs which were domesticated in South-West Asia 12-14,000 years ago. Dogs would be useful assets to hunter-gatherers being capable of acting both as guard dogs and also as playing a role in hunting as they do today, for example when hunting pigs. Yet they were only domesticated after 190,000 years of Homo sapiens sapiens existence. It seems likely the domestication of animals took so long because for a long period of modern human existence they were simply unaware of the usefulness of dogs and other domestic animals and of how to domesticate them. If prehistoric hunter-gatherers did know how to domesticate dogs surely they would have done so.

The view that agriculture was adopted because it offered economic advantages in comparison with hunter-gathering has been questioned recently. Studies of modern hunter-gatherers have suggested they obtained ample calories and protein and consume a wide variety of food. Their life styles are usually preferred to those of farmers and they obtain their food supplies with less labor than is required of farmers. Many studies suggest the hunter-gatherer lifestyle is simply overall superior to that of farmers.[v]

There are however problems with these studies. There are a limited number of them; labor costs are measured in a variety of ways; how does one compare the costs and benefits of sedentism? how does one assess the fact that farmers normally produce a surplus and the costs of storage? Cohen suggests there is probably no method of fairly comparing agriculture with hunter-gathering.[vi] It has been suggested by Hill and Hurtado [vii] that the results of studies of modern hunter-gatherers are so variable that no group 
could be considered to be typical and could be used as an analogue for studying our ancestors. Considerable attention has been directed towards the !Kung San who seem to be an unusually prosperous group of hunter-gatherers.

There is however a much greater problem. It is quite uncertain as to whether studies of modern hunter-gatherers gives any real indication of what life was like for prehistoric hunter-gatherers. Some suggest that as hunter-gatherers only occupy marginal environments in recent times, while before the development of agriculture they would have occupied better lands, they would have been better off in earlier times. However, whether a group is prosperous or not depends not just on the fruitfulness of the land, but also on the size of the population on that land. Poor quality land may support a small population in some affluence while a larger population on better land may not live very well at all. The prosperous !Kung San actually live in a desert but live well presumably due to a low population density on the land.

It is also suggested that the presence of agricultural people would interfere with the ability of hunter-gatherers to move at will and so reduce their economic opportunities and their standard of living. However it is not at all clear that before agriculture hunter-gatherers were able to move at will. Hunter-gatherers tend to have territories and to wander into another band's territory could produce conflict. So it is not necessarily the case that hunter-gatherers in prehistory could wander at will so whether their choices of movement were any more restricted after the development of agriculture, than before is somewhat doubtful.

A more significant matter is that modern hunter-gatherers have a number of benefits not available to prehistoric hunter-gatherers. The first is that modern hunter-gatherers have access to goods and tools that prehistoric hunter-gatherers did not have, due to trade with modern agrarian and industrial societies. Most modern hunter-gatherers have access to iron, making hunting, digging for food and cutting down trees considerably easier. Other products such as pottery, rope and modern medicines might well make the lives of modern hunter-gatherers more comfortable than their prehistoric counter parts. Some modern hunter-gatherers actually hunt with shotguns. One effect of this is that it is likely to give modern hunter-gatherers the edge when it comes to confronting large carnivores. Prehistoric hunter-gatherers armed with flint, bone or ivory tipped spears or arrows may not necessarily have been the top predator in environments containing lions, tigers, leopards, bears, wolves and other fast and well equipped predators. Bears were hunted by the Tlinguit Indians of the north- west coast of America and men were sometimes killed in these hunts. Nowadays the Tlingit use powerful steel traps when hunting bears.[viii] Snake bites and attacks by jaguars represent a significant proportion of deaths among the Ache in eastern Paraguay.[ix] A further benefit modern hunter-gatherers have over their predecessors is that of a higher authority to control and keep order between them. In the event of a dispute between two hunter-gatherer bands there is a much more powerful authority, the government of whatever state the hunter-gatherers live in which will usually prevent them from slaughtering each other. There is no such authority to enforce law and order for prehistoric hunter-gatherers. Disputes may end up being settled by force to the benefit of the strongest or most numerous. Hill \& Hurtado note that among the Ache warfare and accidents account for $73 \%$ of adult deaths. The equivalent figures for the Hiwi are 39\% and for the !Kung-San $11 \%$.

Yet a further advantage modern hunter-gatherers have over their prehistoric counterparts is that modern hunter-gatherers may well receive support in bad years from modern governments. Climates vary and most areas will occasionally suffer from drought which will cause the destruction of the plants and animals hunter-gatherers live on. For prehistoric hunter-gatherers this would mean famine unless they were able to move towards more fertile areas. This would not be easy if the drought covered a large area 
and because prehistoric hunter-gatherers would not necessarily know where the better areas are. Migration to other areas may well involve conflict with other hunter-gatherer bands. Modern hunter-gatherers may well be protected from such disasters but such protection was not available to their prehistoric counterparts. The true test of how people live is not their average or good years but how well they survive in their bad years, as there is little value in having a number of good or average years if they are followed by a single bad year that causes half the band to die of starvation. In these circumstances it seems hardly likely that studies of modern hunter-gatherers will give much idea as to how prehistoric hunter-gatherers lived.

The most convincing explanation of the development of agriculture is that by Robert and Linda Braidwood. They emphasize cultural rather than environmental, plant mutation or population explanations for the development of agriculture. All those explanations have the problem that they cannot explain why agriculture suddenly developed when it did after such a long period of hunter-gathering. The Braidwoods argue that it was improvements in human technology and human knowledge of the environment over time, that lead to the development of agriculture.[x] It is of course impossible to trace the growth in human knowledge in prehistoric people but improvements in human technology are to some extent traceable.

This can be shown in a number of ways. Brian Fagan shows how over time stone tool makers learnt how to make better and better use of a pound of flint to produce successively greater volumes of cutting edge as shown in the case study of Stone Tools. [xi] A similar process can be seen in technological changes that occurred after about 30,000bp. These included improved techniques for the working of raw materials. Before this time technology largely involved the use of only four techniques, those of percussion, whittling scraping and cutting all of which required only a limited range of hand motion. After $30,000 \mathrm{bp}$ new techniques were added including pressure flaking, drilling, twisting grinding and others, which involved different motor abilities than those used previously. Secondly, in the earlier period the main raw materials used were stone, wood and skin. Later on bone, ivory and antler and less importantly shell and clay were added to the original materials. Thirdly, the number of components in composite tools expanded considerably after $30,000 \mathrm{bp}$, increasing the complexity of the tools used. Fourthly, the number of stages involved in manufacturing artifacts significantly increased after 30,000bp. Before 30,000bp manufacturing involved only a short series of single stage operations, while later there were often several stages of manufacture to produce the final product. The number of processes and techniques had increased as had the degree of conceptualization required to manufacture the product.[xii]

In the period between the Middle and Upper Palaeolithic there were substantial improvements in the artifacts available to people. Hunting equipment improved by the use of narrow bone or ivory points for spears which had greater penetrating power than earlier flint tipped spears. Spear throwers and the bow and arrow were also introduced allowing prey to be killed from a greater distance. Cooking was made more effective through the use of cobble-lined hearths which allowed heat to be retained longer and at a more even temperature. Improvements in clothing seem to have been made between the Middle and Upper Palaeolithic providing humans with much better protection against the elements. Eyed needles seem to have been invented around this time. Housing became more sophisticated in the Upper Paleolithic with many structures being made of mammoth bones suggesting that some sort of sophisticated transport device such as sledges were used to move the bones. Art, which played little role in the Middle Paleolithic, became much more extensive in the Upper Paleolithic. Cave paintings appeared in Europe, Australia and North and South Africa. Many artifacts such as bone needles, ivory beads, spear throwers 
and bows had engravings or carving performed on them. Artistic objects such as Venus figurines were traded over considerable distances suggesting the Upper Paleolithic had much improved trade and communications than the Middle Paleolithic.[xiii] Technology developed by hunter-gatherers in the Middle East, to utilize wild cereals, such as stone sickles and underground storage pits were useful to early cereal farmers in the Middle East.

The substantial improvements in the tools, clothing, art and general culture of humankind between the Lower and Upper Paleolithic could only have taken place with a gradually increasing knowledge of how to make better and better use of the materials in the environment. It seems likely that the increased knowledge of the human environment shown by archaeological finds of tools, art and other paleolithic objects would have been matched by a gradually increasing knowledge of the plants and animals humans live off. Hunter-gatherers are known to have a very great knowledge of the plants and animals in their immediate environment, but that does not mean they always had such knowledge. In particular knowledge not directly related to the hunter-gatherers survival, such as how to make plants grow and how to tame animals would not necessarily be immediately known to hunter-gatherers and might only be learnt after a long period of gradually increasing knowledge. As noted earlier, such knowledge was irrelevant to the hunter-gatherer lifestyle, and so may have taken some time to become part of the culture of humankind.

There is very little in the way of hard facts known about the domestication of plants and animals. Most theories as to how this came about contain a fair amount of guesswork. Nevertheless the best theory would seem to be that the knowledge required for the domestication of plants and animals gradually increased over time until enough was acquired to allow the domestications to take place. Theories involving climate change, fortuitous mutations and population pressure causing the domestications all have the problem that such factors could have occurred many times before the agricultural and pastoral revolutions without agriculture and pastoralism being introduced. This strongly suggests that before the agricultural and pastoral revolutions human beings simply did not know how to successfully grow plants and how to domesticate animals.

\section{Endnotes}

[i] Cohen, M. N. (1977) The Food Crisis in Prehistory, Yale University Press; New Haven \& London, 19

[ii] Cohen, M. N. (1977) The Food Crisis in Prehistory, Yale University Press; New Haven \& London, 20-23

[iii] Elkin, A P (1974) The Australian Aborigines, Angus \& Robinson Publishers: London, 51

[iv] Abbie, A A (1970), The Original Australians, A H \& A W Reed: Sydney 200-202

[v] Sahlins,M (1972) Stone Age Economics, Aldine Atherton: Chicago

[vi] Cohen, M. N. (1977) The Food Crisis in Prehistory, Yale University Press; New Haven \& London, 34

[vii] Hill \& Hurtado, 1989, American Scientist, 77(5),436,442

[viii] Oberg, K (1973), The Social Economy of the Tlingit Indians, University of Washington Press, 67-68 [ix] Hill \& Hurtado, 1989, American Scientist, 77(5) 442

[x] (Price \& Gebauer, 1995, 25). (Braidwood, LS \& RJ Prehistoric Village Archaeology in South East Turkey, Oxford: British Archaeological Reports S 138), (Braidwood RJ The Agricultural Revolution, 
Scientific American, 203, 130-141). (Braidwood RJ Prehistoric Men, Glenview, Illinois, Scott Foreman \& Co)

[xi] Fagan, B (1995), People of the Earth: An Introduction to World Pre-History, Harper Collins, New York 111-115

[xii] Dennell,R (1983), European Economic Prehistory, Academic Press: London 81-87

[xiii] Dennell,R (1983), European Economic Prehistory, Academic Press: London 81-87 